\title{
Ueber das Verhalten der Unterchlorsäure gegen Brucin und seine Salze, und den Werth der Brucinreaction zur Nachweisung kleiner Mengen Salpetersäure.
}

Von

\section{Dr. E. Luck.}

Bei Untersuchung einer Zündhölzermasse wurde, um auf salpetersaure Salze zu prüfen, die Reaction mit Brtcin angewendet. Die orangerothe Färbung trat anch ein, aber dieselbe änderte sich nach Zusatz von Zinnsalz nicht in eine violette um.

Dadurch veranlasst, und weil das Vorhandensein von chlorsaurem Kali schon anderwärts festgestellt war, wurde das Verlalten des Brucins zu chlorsaurem Kali nach Zusatz von einigen Tropfen concentrirter Schwefelsäure und nachträglichem Zusatz von Wasser untersucht, und es fand sich, dass Brucin unter diesen Umständen eine ebenso feuerrothe Färbung erzeugt, als wenn Salpetersänre vorhanden ist. Bei Zusatz von Zinnsalz zu der Flüssigkeit findet aber keine violette Färbung, sondern Entfärbung statt.

Es war zunächst die Frage zu lösen, ob diese Reaction durch Unterchlorsäure oder Ueberchlorsäure oder unzersetzte Chlorsäure, welche Substanzen, den Umständen nach, vorhanden sein konnten, hervorgebracht wird.

Zu diesem Zwecke wurde durch Erwärmen von 1 Th. chlorsaurem Kali mit 5 Th. krystallisirter Oxalsäure Unterchlorsäure entwickelt und in Wasser geleitet.

Zerreibt man nun Brucin im Uhrschälchen mit einigen Tropfen dieser wässerigen Unterchlorsäure, so findet keine Farbenveränderung statt, setzt man aber, gleichgültig ob vorher oder nachher, hierzu verdünnte oder concentrirte Schwefelsäure, so tritt sogleich eine starke orangerothe Färbung ein, die auf Zusatz von Zinnsalz verschwindet, indem die Flüssigkeit farblos wird.

Wird dagegen chlorsaures Kali mit verdünnter Schwefelsäure $(1: 5)$ odër mit Kieselflusssäure gerieben und dann Brucin zugesetzt, so findet keine Farbenveränderung statt; demnach giebt unzersetzte Chlorsäure die Reaction nicht, und anch Ueberchlorsäure bringt sie nicht hervor. 
Luck: Ueber das Verhalten der Unterchlorsture gegen Brucin etc. 407

Es ist hieraus ersichtlich, dass unter den oben erwähnten Umständen nur die entstandene Unterchlorsäure die nächste Ursache der Färbung ist, und es ist nur in hohem Grade eigenthümlich und unerklärlich, dass letztere erst dann eintritt, wenn freie Schwefelsäure vorhanden ist, welche, da es gleichgültig ist, ob dieselbe verdünnt oder concentrirt ist, nur dadurch zu wirken scheint, dass sie mit dem freien Brucin ein Salz bildet.

Dieses giebt dann merkwürdiger Weise mit Unterchlorsäure andere Erscheinungen als die freie Basis.

Es erscheint demnach durchaus geboten bei Prüfung auf Salpetersäure mittelst Brucins, sich niemals mit der entstandenen orangerothen Färbung zu begnügen, sondern jedesmal auf die violette Färbung, die nach dem Erwärmen Zinnsalz hervorbringt, hinzuarbeiten. -

Leider ist aber dieser Schlussstein der Brucin-Salpetersäurereaction nicht immer leicht und sicher zu erreichen.

Wenn man erhebliche Mengen freier Salpetersäure auf Brucin einwirken lässt, so tritt die violette Färbung bei Zusatz von Zinnsalz immer und ohne Schwierigkeit ein, wobei jedoch die Bedingung eingehalten werden muss, dass die Probe im Uhrschälchen mindestens noch eine Minute länger erwärmt wird, nachdem schon die orange Färbung in eine hellgelbe übergegangen ist. Unter dieser Voraussetzung dient die Reaction aber vorzugsweise zur Auffindung des Brucins, in welchem Falle man bezüglich des Salpetersäurezusatzes freie Hand hat; sie ist dann sicher und tadellos.

Wird dagegen Salpetersäure gesucht, dann verdient sie letzteres Prädicat nur dann, wenn man es mit nicht allzu geringen Mengen genannter Säure oder mit einer Untersuchung von Substanzen zu thun hat, bei denen, wie z. B. bei Brunnenwassern, Chlorsäure sicher ausgeschlossen ist. -

Ist aber die Salpetersäure nur in sehr geringer Menge vorhanden und an Basen gebunden, dann kann es grosse Schwierigkeiten haben, die für Salpetersäure charakteristische violette Färbung durch Zinnchlorür zu erhalten. In diesem Falle muss, um die Salpetersäure frei zu machen, Schwefelsäure zugesetzt werden, und diese letztere ist, wenn sie ein gewisses Quantum überschreitet, leicht die Ursache des Misslingens.

Nachstehende Versuche lassen das Gesagte erkennen.

Ein Körnchen Brucin wurde in 16 Tropfen englischer Schwefelsäure gelöst, hierzu ein Tropfen Salpetersäure gesetzt und die Flüssigkeit in zwei Uhrgläser (a und b) vertheilt. 
a mit 8 Tropfen Wasser versetzt j aufeinerEisenplatte gleichlang erwärmt, b ohne Wasserzusatz bis hellgelbe Färbung eingetreten.

Nach Zusatz von .Zinnsalz gab $\left\{\begin{array}{l}\text { a starke violette Reaction, } \\ \text { b keine Färbung. }\end{array}\right.$

Der störende Einfluss einer grossen Menge Schwefelsäure ist anch die Ursache, dass man bei Zusatz von Zinnchlorür zu der Flüssigkeit, die man bei Prüfung auf Brucin mittelst salpetersüurehaltiger Schwefelsäure erhält (Fre se ni u s qual. Analyse, 12. Aufl. \$. 238. 7), keine violette Färbung wahrnimmt; derselbe ist um so grösser, wenn die Salpetersüure nur in sehr geringer Menge vorhanden ist und wenn das Erhitzen im Uhrschälchen zu lange gewährt hat, wobei aber immer wieder daran erinnert werden muss, dass auch nicht zu kurz erhitzt werden darf.

Bezüglich der Nachweisung sehr geringer Mengen salpetersaurer Salze durch Brucin, dürften noch nachstehende Versuche von Interesse sein. -

100 Milligramm salpetersaures Natron wurden in 100 CC. Wasser gelöst und von dieser Lösung, die auf $1 \mathrm{Th}$. wasserfreier Salpetersäure 1587 Th. Wasser enthielt, wurden in 5 Uhrgläser, die ich - mit $1-5$ bezeichne, je 3 Tropfen gebracht. Ferner wurde in dieselben in steigender Menge concentrirte Schwefelsüure getropft, nämlich 1, 2, 3, 4 und 5 Tropfen, und zuletzt in jedes ein kleines Körnchen Brucin. - Es entstand in 3,4 und 5 alsbald orange Fürbung, dagegen blieben 1 and 2 zunächst ungefärbt, und erst nachdem sämmtliche Nummern auf einer heissen Eisenplatte erwärmt und 3-5 längst hellgelb geworden, fingen 1 und 2 an sich orangeroth zn färben.

Es gaben nach Zusatz von Zinnchlorür die Schälchen 2, 4, 5 intensive violette Färbung, No. 1 gab dieselbe zuerst nicht, wohl aber sehr stark, als der Verdampfungsrückstand, der nur aus etwa 1 Tropfen bestand, wieder mit 3-4 Tropfen Wasser verdünnt und von Neuem einige Zeit erhitzt wurde. No. 3 gab ein negatives Resultat.

Es geht hieraus hervor, dass man bei kleinen Mengen salpetersaurer Salze und bei Anwendung von nur wenig Schwefelsäure, länger erhitzen muss, dass aber auch die Reaction stärker eintritt, als wenn man den Vorgang durch Anwendung von einer grösseren Menge Schwefelsüure beschleunigt. Die Stärke der Reaction nimmt in dem Maasse ab, als die Menge oder Concentration der vorhandenen Schwefelsüure steigt.

Diese Versuche wurden mit fast gleichem Erfolge mehrmals wiederholt, aber fast immer zeigte es sich, dass 1 oder 2 Proben, und zwar nicht immer die von gleichem Schwefelsäuregehalt, negative oder sehr undeutliche Reactionen gaben, so dass man jedenfalls gut thun wird, wenn man 
mit der zu prüfenden Substanz gleichzeitig mehrere Proben ausführt, bei denen man bezüglich der Zeitdauer des Erhitzens im Uhrschälchen Unterschiede eintreten lässt. Man nehme ferner nicht mehr als 1-2 Tropfen Schwefelsäure.

Nur bei Einhalten dieser Bedingungen kann die besprochene Reaction zur Nachweisung der Salpetersäure angewendet werden, und ausserdem erinnere man sich, dass bei sehr geringen Mengen Salpetersäure und Anwendung von nur 1 bis 2 Tropfen Schwefelsäure die rothe Färbung erst nach einiger Zeit beim Erwärmen sich zeigt.

Aus Vorstehendem geht demnach hervor, dass die Nachweisung der Salpetersäure durch Brucin mit grosser Vorsicht ausgeführt werden muss, und dass diese Methode derjenigen mit Phenolschwefelsäure an Sicherheit und Empfindlichkeit nachsteht. -

\section{Löslichkeit des Weinsteins in wässrigen und alkoholischen Fliissigkeiten, Prïfung der Berthelot-Fleurieu'schen Methode zur Bestimmung des Weinsteins und der Weinsäure im Wein,}

$$
\text { Von }
$$

Ed. Kissel,

Assistenten an der agricultur-chemischen Versuchsstation zu Wiesbaden.

Da die hiesige agricultur-chemische Versuchsstation ihr Hauptaugenmerk auf den Weinbau und seine Producte zu richten hat und Weinanalysen einen grossen Theil ihrer Thätigkeit bilden, so war es von der grössten Wichtigkeit die mannigfaltigen Methoden, welche zur Bestimmung der im Wein enthaltenen Körper vorgeschlagen sind, einer sorgfültigen Prüfung zu unterwerfen, um sich von der Anwendbarkeit derselben zu überzeugen. Ueberhaupt kann ein näheres Studiren der Eigenschaften und des Verhaltens der Weinbestandtheile nur günstig und fördernd für die Kenntniss des Weins wirken.

Unter den im Wein enthaltenen sauren Salzen nimmt das saure weinsaure Kali, der Weinstein, eine hervorragende Stelle ein; es macht einen Theil der Gesammtsäure aus, ist überhaupt einer der wesentlichen Bestandtheile des Weins, seine angenehme Säure trägt zum Wohlge- 